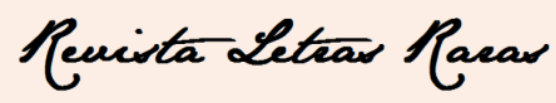

ISSN: 2317-2347 - Vol. 5, Ano 5, № 2 - 2016

\title{
Personagens femininas e escritoras na Literatura Francófona da África Subsaariana
}

Fernanda Murad Machado*

Resumo: As escritoras e personagens africanas tardaram a ter um papel marcante no universo da literatura francófona. Se esse campo literário passou a se desenvolver na África subsaariana nos anos 1930 e 1940, as mulheres, marginalizadas dos processos de escolarização coloniais, consagraram-se como autoras apenas décadas mais tarde, na passagem de 1970 e 1980. O presente artigo tem como objetivo fazer um breve panorama histórico da presença feminina na literatura francófona da África subsaariana a partir de diferentes perspectivas. Por um lado, trata-se de analisar a evolução da representação da mulher nesse campo literário e a emergência de obras de autoria feminina, desde a passagem da literatura oral para a literatura escrita, sob a colonização europeia, até o período pósindependências. Por outro, trata-se de examinar as principais temáticas abordadas por escritoras no universo da prosa narrativas epistolares, autobiografias, romances e novelas - e a diversificação destas ao longo do tempo.

Palavras-chave: Mulheres na literatura; Literatura africana; Escolarização feminina; História da África subsaariana.

\section{Female characters and writers in the Francophone Literature of Subsaarian Africa}

\begin{abstract}
The African female writers and characters take long to have a remarkable role in the universe of Francophone literature. This literary field began to grow in sub-Saharan Africa in the 1930s and 1940s, but the women, marginalized of colonial schooling processes, were recognized as authors only decades later, in the 1970s and 1980s. This article aims to give a brief historical overview of women's presence in Francophone literature in sub-Saharan Africa from different perspectives. On the one hand, we are going to analyze the evolution of women's representation in this literary field and the emergence of books written by women, from the passage of oral literature to written literature under European colonization, to the post-independence period. On the other, we are going to examine the most recurring themes in her books in the prose universe - epistolary narratives, autobiographies, novels and short-stories over time.
\end{abstract}

Keywords: Women in literature; African literature; Female schooling; History of sub-Saharan Africa.

\section{Introdução}

Invisíveis, secundárias ou idealizadas, as mulheres tardaram a ter um papel marcante no universo da literatura francófona africana, essencialmente masculina até as décadas de 1970 e 1980. Se já no imediato pós-independência, nos anos 1960, os escritores começaram a explorar o tema da condição social feminina em romances e, sobretudo, em novelas, foi apenas com a emergência das primeiras escritoras que a mulher africana se tornou de fato protagonista. Seus escritos iniciais

\footnotetext{
* Possui graduação em Letras Modernas (Universidade Paris IV Sorbonne, 2004), DEA em Literatura e Língua Francesa (Centre International d'Études Francophones - Universidade Paris IV Sorbonne, 2005) e doutorado em Literatura e Língua Francesa (Centre International d'Études Francophones - Universidade Paris IV Sorbonne, 2010). Desenvolveu pós-doutorado, com apoio da FAPESP, no Departamento de Letras Modernas, da FFLCH-USP. Tem experiência na área de Letras, com ênfase em Literatura Francesa, Literatura Africana Francófona, Teoria Literária, Língua Francesa e Tradução.
} 


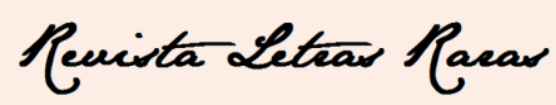

ISSN: 2317-2347 - Vol. 5, Ano 5, № 2 - 2016

traduzem a necessidade de falar, de romper o silêncio e de se contar, daí a escolha de narrativas epistolares, de romances-reportagens e de autobiografias como formas privilegiadas (CAZENAVE; KINGUÉ, 1997, p. 641). A abordagem de assuntos tabu ou problemáticos da esfera sociopolítica fez com que, progressivamente, as mulheres deixassem de ter como foco apenas sua própria realidade e se apropriassem de campos estilísticos e temáticos da literatura dominados por autores homens.

\section{Narradoras e personagens femininas na literatura oral}

Nas culturas de tradição oral, prevalecentes em toda a África subsaariana antes da colonização europeia, a literatura era transmitida tanto por homens quanto por mulheres. Na África ocidental, entre os povos uólofes, dogons ou fulas, por exemplo, as contadoras eram personalidades proeminentes e desempenhavam um papel social de primeiro plano. Elas transmitiam composições orais livres, que acompanhavam atividades cotidianas femininas, como cantos de trabalho ou cantigas de ninar, mas também gêneros mais estruturados e com regras rígidas em ocasiões específicas, como lamentações fúnebres ou elegias, panegíricos, encantações e provérbios (SUTHERLAND-ADDY, DIAW, 2007, p. 37). Algumas tradicionalistas tinham ainda a função de conservar as narrativas iniciáticas contadas nos rituais de passagem simbólicos na vida das meninas e das mulheres. Por sua teatralidade, a linguagem sofisticada e o apuro estético, a fala artística das contadoras não se distinguia da de seus homólogos masculinos. Porém, para públicos mais amplos, a transmissão de certos gêneros e temas era vedada a elas. Ainda que algumas mulheres fossem conhecedoras da história e das genealogias locais, a narração de epopeias e poemas épicos era exclusividade dos tradicionalistas de sexo masculino (SUTHERLAND-ADDY, DIAW, 2007, pp. 42-43). Assim como a contação de contos, enigmas e adivinhações.

Quando a literatura oral começou a ser coletada e publicada em francês por europeus, ao longo do século XIX, e por africanos, a partir das décadas de 1930 e 1940, o repertório tradicional transmitido pelas mulheres foi omitido. Os gêneros privilegiados pelos institutos africanistas, editoras e revistas foram o conto e, em menor escala, a epopeia. Nesse processo, não apenas desapareceu a narradora africana, como também se tornaram mais raros os personagens femininos no universo literário.

Nas epopeias, mesmo quando exercem uma função essencial no desenrolar da ação, por aconselharem ou auxiliarem os heróis com seus poderes naturais ou sobrenaturais, as mulheres - 


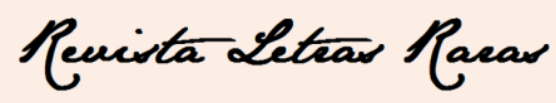

ISSN: 2317-2347 - Vol. 5, Ano 5, № 2 - 2016

mães, esposas ou filhas - são sempre coadjuvantes. Também nos contos elas pouco se destacam. Aparecem em narrativas etiológicas que explicam o surgimento da mulher primordial ou a formação dos primeiros casais, e são geralmente focadas nas diferenças e na incompreensão entre mulheres e homens - sobretudo destes últimos em relação a elas ${ }^{1}$. O ponto de vista masculino geralmente prevalece mesmo nas histórias que tratam de questões relacionadas diretamente à condição feminina, como a rivalidade no seio do casamento poligâmico, geralmente marcada pela oposição entre uma co-esposa boa e outra má, ou ainda conflitos desencadeados por sentimentos e características associados tradicionalmente à personalidade feminina, como a vaidade, o ciúmes, a esperteza e o poder de manipulação. Quando o tema, bastante raro, da emancipação feminina é abordado, como no conto escrito pelo guineano Djibril Tamsir Niane, "La femme qui voulut être l'égale" de l'homme [A mulher que queria ser igual ao homem] (1985), trata-se de uma emancipação não realizada, com um desfecho trágico e que reafirma os papéis distintos a serem ocupados por homens e mulheres no seio da comunidade.

\section{Personagens femininos na obra de escritores africanos modernos}

Contemporânea dos inícios da produção de contos escritos, a poesia da negritude, publicada por africanos e afrodescendentes em Paris, celebrava a sensualidade da mulher negra, etérea e idealizada. Apesar da dimensão política das obras e da participação de algumas mulheres nos debates e círculos literários que deram origem a esse movimento, como as irmãs $\mathrm{Nardal}^{2}$, não há uma busca por personagens femininos complexos e problemáticos. A mulher é essencialmente o objeto da contemplação de um eu lírico masculino. Musa inspiradora, ora desejável, ora materna e fértil, ela aparece frequentemente como a personificação da beleza do continente africano, através

\footnotetext{
${ }^{1}$ Em sua intervenção no Primeiro Congresso dos Escritores e Artistas Negros (Paris, 1956), o marfinense Bernard Dadié narra um conto com essa temática. Quando o deus Twashtri terminou de criar o mundo e decidiu fazer a mulher, percebeu que já usara todos os elementos sólidos para o homem. Depois de muito meditar, empregou uma pequena parcela de todas as suas criações para constituir o ser feminino: a redondeza da lua e as curvas das vinhas, a alegria do raio de sol e as lágrimas das nuvens, a maciez do peito do papagaio e a dureza do diamante, a doçura do mel e a crueldade do tigre, etc. Exaustos e incapazes de lidar com uma criatura tão incoerente, os homens logo devolveram a mulher a Twashtri. Pouco depois, voltaram desesperados para buscá-la, e novamente a devolveram. Depois de várias idas e vindas, Twashtri perdeu a paciência e mandou que os homens levassem a mulher de uma vez por todas. Eles se foram inconsoláveis, dizendo que não podiam viver com essa criatura. Mas também não podiam viver sem ela. O conto se fecha com um provérbio: "o fogo que te queimará é o mesmo que te esquenta" (DADIÉ, p. 1957, p. 170).

${ }^{2}$ Foi no salão literário organizado pelas irmãs martinicanas Paulette, Jane e Andrée Nardal que nasceu o projeto de La revue du monde noir (1931-1932), uma das primeiras revistas parisienses a reunir estudantes e intelectuais negros das Antilhas, dos Estados Unidos e da África. Paulette e Andrée participaram ativamente da revista com artigos de sua autoria.
} 


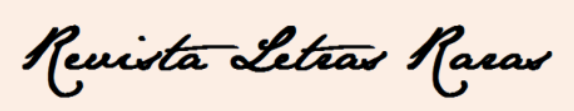

ISSN: 2317-2347 - Vol. 5, Ano 5, № 2 - 2016

de metáforas geográficas e vegetais, como ilustram os versos do célebre poema de Léopold Sédar Senghor "Femme noire" [Mulher negra] (1945):

Mulher nua, mulher obscura

Fruto maduro de carne firme, sombrias êxtases do vinho negro, boca que faz] lírica a minha boca

Savana de horizontes puros, savana que se arrepia com as carícias ferventes do] Vento do leste" (1990, p. 16, tradução minha) ${ }^{3}$.

Os personagens femininos passaram a ter uma identidade mais definida a partir da década de 1960, nos escritos francófonos do pós-independências. Nesse contexto - em que a produção de romances e novelas ganhou força e os problemas cotidianos relacionados às novas configurações sociopolíticas tornaram-se temas literários centrais - a situação da mulher começou a ser explorada de maneira menos caricata e mais crítica por escritores como, por exemplo, Emmanuel Dongala, René Philombe, Francis Bebey, e, especialmente Sembène Ousmane. Essa temática, abordada sob ângulos diversos, transpassa toda a obra deste último. Em seus livros e filmes, ele lança luz sobre o patriarcalismo das sociedades tradicionais e a manutenção de práticas arcaicas, a resistência silenciosa das mulheres sob a colonização ou ainda os dissabores de mães solteiras e mulheres exploradas nas sociedades contemporâneas. Personagens fortes, frequentemente com destinos trágicos, as mulheres nas obras de Ousmane não são propriamente heroicas ou revolucionárias, mas se afirmam por não terem escolha e assumem o poder quando os homens sucumbem (PFAFF, 2009, p. 156).

\section{Escolarização feminina e primeiros escritos}

Os anos que se seguiram às independências foram marcados igualmente pelo surgimento das primeiras escritoras africanas no campo da francofonia. O início tardio da produção literária das mulheres, com décadas de defasagem em relação à dos homens, está diretamente relacionado ao acesso desigual ao ensino e à alfabetização. Fenômeno ainda pouco estudado, a escolarização feminina desenvolveu-se lentamente e de modo irregular durante o período colonial. Assumida inicialmente por congregações religiosas, a instrução elementar era focada nas tarefas domésticas e

\footnotetext{
${ }^{3}$ « Femme nue, femme obscure

Fruit mûr à la chair ferme, sombres extases du vin noir, bouche qui fais lyrique ma bouche

Savane aux horizons purs, savane qui frémis aux caresses ferventes du Vent d'Est ».
} 


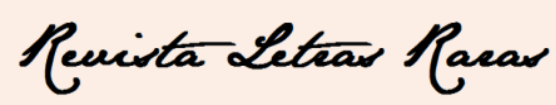

ISSN: 2317-2347 - Vol. 5, Ano 5, № 2 - 2016

na preparação para a maternidade, de modo que as meninas aprendiam apenas rudimentos da língua francesa (HERZBERGER, 2000, p. 26).

Em 1938, foi fundada a Escola Normal de Rufisque, nas imediações de Dacar, no Senegal. Aberta às meninas de todos os territórios da África Ocidental Francesa, a instituição tinha o objetivo de formar as primeiras professoras primárias africanas e de educar as futuras esposas dos nativos "evoluídos", diplomados nas escolas superiores masculinas existentes (SUTHERLAND-ADDY, DIAW, 2007, p. 92). Os interesses políticos e ideológicos que determinaram a criação desta foram motivados menos pela preocupação de favorecer o desenvolvimento das meninas do que pelo objetivo de inculcar valores e comportamentos suscetíveis de enraizar ainda mais profundamente a presença francesa nas colônias. Ainda assim, a Escola Normal de Rufisque constituiu uma verdadeira revolução no plano das perspectivas escolares e profissionais oferecidas às jovens africanas pela administração francesa (BARTHÉLÉMY, 2003, p. 371). Principal via de acesso ao mercado de trabalho e a certo grau de emancipação, frequentar a escola era o privilégio de poucas. Além das vagas serem limitadas, havia uma grande resistência cultural das populações locais à escolarização das meninas, principalmente nos meios rurais. A isto se soma o fato de que muitas alunas tinham de abandonar os estudos precocemente para se casar (HERZBERGER, 2000, p. 28)..

Apesar de não haver registros de obras propriamente literárias escritas durante a era colonial pelas africanas formadas, foram conservados alguns textos pontuais que constituem fragmentos reveladores do novo papel das jovens letradas nas relações familiares, bem como da sociedade colonial retratada do ponto de vista feminino. Trata-se, sobretudo, de petições dirigidas aos governadores das colônias - de mães solicitando a liberação de filhos encarcerados ou de viúvas defendendo questões de propriedade -, e de cartas escritas por adolescentes que frequentavam a escola colonial (VOLET, 2008).

Em um dos primeiros números da revista histórica Présence Africaine, em 1950, Charles Béart, diretor da escola masculina William Ponty, publicou uma série de cartas, sob o título "Intimité: lettres de la fiancée" [Intimidade: cartas da namorada], precedidas da seguinte observação: “[...] um de meus jovens amigos africanos me entregou com alguns comentários explicativos as cartas que lhe enviou uma moça, sua colega de estudos: quarenta e três cartas distribuídas ao longo de quatro anos"4 (BÉART, 1950, p. 273, tradução minha). Por seu caráter autobiográfico, a correspondência de Juliette a Fred (pseudônimos criados para a publicação),

\footnotetext{
${ }^{4}$ «Un de mes jeunes amis africains m’a remis avec quelques commentaires explicatifs les lettres que lui a adressées une jeune fille, sa camarade d'études : quarante-trois lettres reparties sur quatre ans »
} 


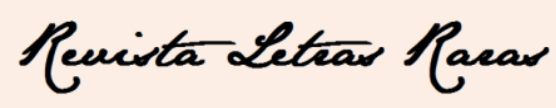

ISSN: 2317-2347 - Vol. 5, Ano 5, № 2 - 2016

mantida entre 1939 e 1942, constitui um esboço de romance epistolar, de estilo simples e bastante ingênuo, no qual a estudante primária com aspirações de se tornar professora evoca suas atividades do dia a dia, e declara seu amor ao rapaz que trabalha como bedel em seu internato.

A imprensa local constituiu também um espaço inicial para que as jovens letradas expressassem publicamente questões pessoais e suas opiniões sobre a sociedade contemporânea. O tema que se destaca, em cartas de leitoras e em depoimentos, é a educação e, em particular, os preconceitos contra a escolarização feminina (HERZBERGER, 2000, p. 36). Em 12 de março de 1942, o tabloide semanal recém-lançado Dakar-Jeunesse publicou um texto anônimo intitulado "Je suis une Africaine... J'ai vingt-ans" [Sou uma africana... Tenho vinte anos], no qual uma jovem togolesa expressa orgulho por suas origens e defende sua condição de estudante:

Gosto da natureza bela e calma, da flor e de seu perfume, do sol ofuscante e abrasador de minha África, da noite escura e estrelada, e até do chilrear lúgubre da coruja ao entardecer, e sou até indulgente com os céticos, aqueles que criticam a nossa Escola Normal, a nossa "Casa", sem conhecê-la, e acreditam que a mulher nativa permanecerá eternamente impessoal, sem dignidade, uma serviçal resignada que o homem pode tomar para si ou abandonar ao sabor de seus caprichos (citado por HERZBERGER, 2000, p. 37, tradução minha) $)^{5}$

No único livro em francês publicado por uma africana do qual se tem conhecimento no período, lançado já às vésperas das independências, em $1958^{6}$, o tom e a temática da narração são bastante semelhantes aos das cartas e textos da imprensa. Escrito pela camaronesa Marie-Claire Matip, Ngonda - que significa "menininha" no idioma bassa - é um relato autobiográfico, de cerca de 50 páginas, escrito pela autora na adolescência, quando frequentava a Escola Moderna de Moças de Douala. A narrativa, constituída de uma sucessão de pequenos capítulos que seguem a cronologia de vida da menina, do nascimento ao casamento, é estruturada em torno de três personagens femininos: a avó, guardiã das tradições ancestrais; a mãe, camponesa trabalhadora preocupada apenas em alimentar a família numerosa; e Ngonda, a heroína, menina com um destino diferente do das outras mulheres de seu clã e símbolo da nova condição feminina. Esse texto, o único publicado por Matip, foi bastante difundido em seu país de origem pela Igreja evangélica, responsável por sua impressão. Mencionado nos compêndios Bibliographie. Auteurs africains et

\footnotetext{
${ }^{5}$ « J'aime la nature belle et calme, la fleur et son parfum, le soleil ébluissant et brulant de mon Afrique, la nuit sombre et étoilée, même le cri lugubre du hibou le soir et je suis même indulgente aux septiques [sic], à ceux qui critiquent notre École Normale, notre « Maison », sans connaître et qui pensent qu'éternellement, la femme indigène demeurera impersonnelle, sans dignité, la servante résignée qu'un homme peut prendre ou délaisser suivant son caprice. »

${ }^{6}$ No campo da anglofonia, o primeiro livro publicado por uma africana foi o romance da nigeriana Flora Nwapa, Efuru, em 1966.
} 


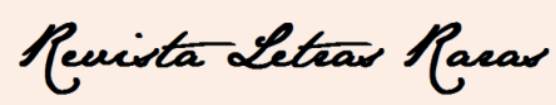

ISSN: 2317-2347 - Vol. 5, Ano 5, № 2 - 2016

malgaches de langue française (1965) [Bibliografia. Autores africanos e malgaxes de língua francesa], de Thérèse Baratte-Eno Belinga, e Le livre Camerounais et ses auteurs (1984) [O livro camaronês e seus autores], de René Philombe, Ngonda nunca foi objeto de um estudo crítico (HERZBERGER, 2000, p. 45) - o que se explica por seu interesse mais histórico do que propriamente literário.

Esses primeiros escritos sob o regime colonial têm assim em comum o fato de girarem em torno de experiências pessoais de mulheres muito jovens, pertencentes a um grupo restrito de alunas do sistema de ensino ocidental, que sonhavam ocupar funções sociais outras que não aquelas que lhes eram tradicionalmente atribuídas. Elas descrevem apenas os aspectos positivos da instituição escolar e da aprendizagem da língua da metrópole, ao contrário de escritores do sexo masculino como o maliano Hampâté Bâ e o marfinense Bernard Dadié que, com humor ou virulência, denunciam em suas obras a maneira impositiva como os meninos eram recrutados para as escolas e o projeto de aculturação intrínseco aos programas educacionais.

\section{Literatura feminina no pós-independências}

Os anos 1960 marcaram uma participação mais expressiva das africanas na imprensa local $^{7}$, porém, foi preciso esperar até meados da década de 1970 para que a escrita feminina começasse a circular e ser conhecida através de livros. No momento em que os movimentos feministas se afirmavam no contexto internacional, editoras como Présence Africaine e NEA (Nouvelles Éditions Africaines) lançaram obras de autoras africanas engajadas na liberação feminina e na denúncia do patriarcalismo. Apesar de certa continuidade temática e estilística em relação à produção das décadas anteriores - particularmente no que se refere à subjetividade e ao espaço central atribuído às experiências pessoais das escritoras-narradoras - o horizonte ampliou-se significativamente. Os acontecimentos da esfera pública ganharam o primeiro plano nos textos daquelas que se consideravam "porta-vozes de suas coirmãs que não [tinham] a possibilidade de se expressar por escrito" (HERZBERGER, 2000, p. 24, tradução minha) ${ }^{8}$.

\footnotetext{
${ }^{7}$ Uma das figuras mais proeminentes foi a senegalesa Annette Mbaye d'Erneville, primeira radialista da África francófona. Ainda em 1957, lançou a revista feminina Femmes de soleil, que ficou mais conhecida a partir de 1963, quando passou a se chamar Awa (CAZENAVE, 2009, p. 11). Entre seus textos na imprensa da época, destacam-se a novela "La bague de cuivre et d'argent" [O anel de cobre e de prata] premiada em um concurso organizado em 1961 pelo jornal Jeune Afrique e o artigo "Une victoire des Sénégalaises" [Uma vitória das senegalesas] de 21 de janeiro de 1968 para o mesmo jornal.

8 « les romancières se considèrent comme porte-parole de leurs consoeurs qui ne sont pas en mesure de s'exprimer par écrit »
} 


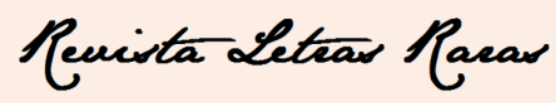

ISSN: 2317-2347 - Vol. 5, Ano 5, № 2 - 2016

A maioria dos livros publicados nessa década, de caráter puramente documental, buscava situar a mulher dentro dos grandes processos históricos e sociais que marcaram o século XX africano. Uma das publicações mais notáveis, por focalizar a ação política feminina sob a colonização francesa, é La marche des femmes sur Grand-Bassam (1975) [A marcha das mulheres sobre Grand-Bassam], da professora de história marfinense Henriette Diabaté9 . Já em Femme d'Afrique: la vie d'Aoua Keita racontée par elle-même [Mulher da África: a vida de Aoua Keita contada por ela mesma], lançada no mesmo ano, a autora, uma maliana sexagenária, parteira e militante do RDA, denuncia não só os abusos das autoridades coloniais como a resistência de seus compatriotas em aceitar os novos direitos conquistados pelas mulheres. Destaca-se ainda La parole aux négresses (1978) [A palavra às negras], da antropóloga senegalesa Awa Thiam, uma coletânea de entrevistas realizadas com mulheres do Senegal, do Mali e da Guiné, de diferentes origens sociais e idades. A autora aborda formas de violência física e moral baseadas em práticas tradicionais e modernas, como os casamentos forçados e a poligamia, as mutilações sexuais e os tratamentos estéticos de branqueamento da pele. Apesar da riqueza de informações e da relevância das questões levantadas por essas obras, a única que teve alguma repercussão foi La parole aux négresses, pelo tom e o conteúdo provocadores, mas sobretudo pela abordagem do tema da excisão feminina ${ }^{10}$ - inédito em textos africanos (VOLET, 2008).

A consagração de autoras africanas viria com a publicação de duas obras de ficção em 1979: Une si longue lettre [Uma carta tão longa], da senegalesa Mariama Bâ, e La Grève des Battù ou Les déchets humains [A greve dos Battù ou Os dejetos humanos], da senegalesa Aminata Sow Fall ${ }^{11}$. Traduzidas para várias línguas, elas tiveram um sucesso imediato, impulsionado pelo reconhecimento de instituições literárias internacionais. A primeira recebeu o prêmio Noma, na Feira de Frankfurt (1980), e a segunda, o Grand Prix Littéraire de l'Afrique Noire (1980), além de ter sido indicada em 1979 ao Goncourt, principal condecoração literária francesa. De temáticas bastantes diversas, ambas têm em comum a dimensão estética e a tensão dramática ausentes nas

\footnotetext{
9 A obra relata a famosa marcha de 24 de dezembro de 1949, de Abidjan a Grand-Bassam, onde estavam encarcerados responsáveis do RDA - federação de partidos de diferentes regiões do Império colonial francês, e uma das principais forças políticas africanas na luta pela conquista das independências. A mobilização reuniu milhares de mulheres e culminou em um terrível massacre por parte das autoridades francesas.

${ }^{10}$ A excisão feminina, também conhecida como circuncisão feminina, é a remoção ritualística de parte ou de todo o órgão sexual externo da mulher. Ainda hoje é praticada, de maneira pontual ou generalizada, em 29 países africanos. Na Guiné e no Djibuti, por exemplo, estima-se que mais $90 \%$ das mulheres passaram pela operação. UNICEF, "Female Genital Mutilation /Cutting", 2013. Disponível em: http:/www.childinfo.org/files/FGCM_Lo_res.pdf $>$. Acesso em 20 jun. 2015.

${ }^{11}$ No caso de Aminata Sow Fall, trata-se da segunda obra, a primeira sendo o romance Le Revenant [A assombração], de 1976.
} 


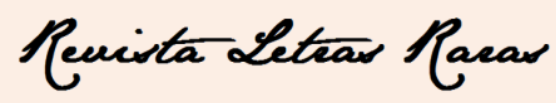

ISSN: 2317-2347 - Vol. 5, Ano 5, № 2 - 2016

outras publicações femininas já citadas. Une si longue lettre é um romance epistolar, no qual Ramatoulaye, uma professora primária, narra a uma amiga de juventude a decepção e o sofrimento por ter sido abandonada pelo marido, que se casou sem avisá-la com uma segunda esposa - colega de escola de sua filha. La grève des Battù gira em torno de uma revolta imaginária dos mendigos de Dacar: brutalizados pelas autoridades durante uma grande ação de higienização em prol do turismo, eles decidem interromper suas atividades, causando furor entre os habitantes locais, que acreditam que a concessão de esmolas os protege da infelicidade, do insucesso e das doenças.

Marcos na história da escrita francófona na África subsaariana, essas obras prepararam o terreno para uma produção feminina que floresceu na década de 1980 e que vem proliferando e se diversificando desde então (CAZENAVE, 2009, p. 11). Como Mariama Bâ, muitas escritoras continuaram explorando questões diretamente relacionadas à condição feminina, ao casamento e à opressão familiar e social sofrida pelas mulheres. Seus romances passaram a tratar de maneira mais direta temas tabu, como o imaginário sexual feminino ou a prostituição - a exemplo de Le Baobab fou (1983) [O baobá louco], da senegalesa Ken Bugul, e C'est le soleil qui m'a brûlée (1987) [Foi o sol que me queimou], da camaronesa Calixthe Beyala,-, e a dar ênfase às vitórias, mesmo ínfimas, contra o entorno hostil à emancipação das mulheres - como La révolte d'Affiba (1985) [A revolta de Affiba] da marfinense Régina Yaou. Ainda nos anos 1980, as escritoras iniciaram um movimento de apropriação de gêneros, temáticas e perspectivas associados ao universo literário masculino. Nesse aspecto, Aminata Sow Fall, foi novamente precursora, com a sátira política, L'exPère de la nation (1987) [O ex-Pai da nação]. Destacam-se também obras protagonizadas por personagens masculinos, como L'Amour-cent-vies (1988) [O amor-cem-vidas], narrativa híbrida, subintitulada "romance-canto" pela camaronesa Liking Werewere (VOLET, 2014).

Nas décadas seguintes, surgiram progressivamente novas problemáticas relacionadas aos contextos políticos e sociais contemporâneos. Como nas obras publicadas por escritores homens, as difíceis situações enfrentadas pelas populações africanas ganharam cada vez mais espaço no universo literário. A pandemia de AIDS, que atinge principalmente mulheres em toda a região subsaariana do continente, é o tema da novela "La marche aveugle" [A marcha cega] da senegalesa Sokhna Benga (2006). As guerras fratricidas, a tortura ou repressão política passaram também a ser narradas do ponto de vista feminino. Assim, Scholastique Mukasonga, em L'Iguifou. Nouvelles rwandaises (2010) [O Iguifou. Novelas ruandesas], evoca a partir de ângulos diversos o contexto em que ocorreram os terríveis massacres que fizeram mais de 800 mil mortos, em 1994; enquanto a congolesa Liss Kihindou recorre a esse mesmo gênero breve para descrever a situação conturbada 


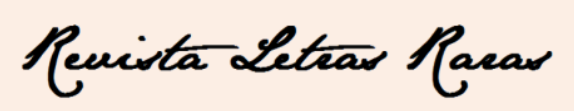

ISSN: 2317-2347 - Vol. 5, Ano 5, № 2 - 2016

de seu país, na coletânea Détonations et folie (2007) [Explosões e loucura] (VOLET, 2014). Outra temática hoje recorrente entre as mulheres, e da qual a senegalesa Fatou Diome e a camaronesa Léonora Miano são duas importantes expoentes, é a vida fora da África, na Europa ou na América, e em particular, o complexo cotidiano dos imigrantes africanos.

\section{Considerações finais}

Ao longo de quatro décadas de produção literária, desmoronaram assim, pouco a pouco, as fronteiras inicialmente tão demarcadas entre a estrutura formal e a temática das obras publicadas por mulheres e homens na África francófona subsaariana. Do mesmo modo que nos anos 1940 a poesia precursora da negritude tinha como foco a criação de novas imagens do homem negro, em oposição aos estereótipos impostos pelo Ocidente branco, os livros de autoria feminina, que despontaram trinta anos mais tarde, tinham a condição da mulher nas sociedades africanas como tema principal. Em ambos os casos, sem que as especificidades identitárias dos autores deixassem de ser exploradas, houve um abandono progressivo dos dualismos, às vezes caricatos, que opunham homens e mulheres, negros e brancos, colonizados e colonizadores, e uma maior abertura para "perspectivas novas que permitam uma compreensão mais global dos indivíduos e das relações do continente africano com o resto do mundo" (VOLET, 2014, tradução minha) ${ }^{12}$.

\section{Referências}

BARTHÉLÉMY, P. Instruction ou éducation. La formation des Africaines à l'École normale d'institutrices de l'AOF de 1938 à 1958. Cahiers d'Études Africaines, n. 169-170, 2003, pp. 371388.

BÉART, C. Intimité: lettres de la fiancée. Présence Africaine, n. 8-9, pp. 271-288, 1950.

CAZENAVE, O. 40 ans d'écriture au féminin. Notre Librairie, n.172, pp. 9-14, jan.-março de 2009.

CAZENAVE, O.; KINGUÉ, A. Pour l'enseignement des écrivains africains dans les cours de français. The French Review, n.5, vol. 70, p. 641-657, 1997.

\footnotetext{
12 « des perspectives nouvelles et permet l'amorce d'une compréhension globale des individus et des rapports du continent africain avec le reste du monde »
} 


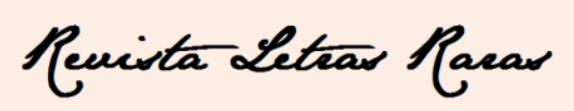

ISSN: 2317-2347 - Vol. 5, Ano 5, № 2 - 2016

DADIÉ, B. Le rôle de la légende dans la Culture Populaire des Noirs d'Afrique. Présence Africaine. Ier Congrès International des Écrivains et Artistes Noirs, Paris, no 14-15, pp. 165-174, 1957.

HERZBERGER, F. Littérature féminine francofone d'Afrique Noire. Paris: L'Harmattan, 2000.

NIANE, D. La femme qui voulut être l'égale de l'homme. In: Contes d'hier et d'aujourd'hui. Paris/Dacar: Présence Africaine, 1985.

PFAFF, F. Les femmes africaines dans les films de Sembène. Africultures, $\mathrm{n}^{\circ}$ 76, "Sembène Ousmane (1923-2007)", pp. 149-156, 2009.

SENGHOR, L. S. Femme noire. Oeuvre poétique. Paris: Éditions du Seuil, 1990.

SUTHERLAND-ADDY, E.; DIAW, A. (org.). Des femmes écrivent l'Afrique. L'Afrique de l'Ouest et le Sahel. Paris: Karthala, 2007.

VOLET, J.-M. L'Afrique écrite au féminin. Que sont les écrivaines de jadis devenues, 2008. Disponível em: http://aflit.arts.uwa.edu.au. Acesso em 25 jun. 2015.

VOLET, J.-M. Rendre la parole agissante. L'Afrique écrite au féminin depuis les années 1960, 2014. Disponível em: http://aflit.arts.uwa.edu.au/independant_20e_fr.html. Acesso em 25 jun. 2015.

Recebido em : 27/07/2016

Aceito em : 01/08/2016 